\title{
A Cross-sectional Assessment of Knowledge, Attitude, and Practices toward Oral Hygiene among Schoolchildren in Jimma, Ethiopia
}

\author{
Renu Rawat ${ }^{1}$, Gunjan S Aswal ${ }^{2} \odot$, Vinod KR Kumar ${ }^{3}$, Vishwanath Gurumurthy ${ }^{4}$, Soumya Vishwanath ${ }^{5}$, Dinesh F Swamy ${ }^{6} \odot$
}

\begin{abstract}
Aim: The purpose of this study is to assess the knowledge, attitude, and practices toward oral hygiene among schoolchildren in Jimma, Ethiopia, using a questionnaire.

Materials and methods: For this descriptive study, schoolchildren $(n=580)$ aged between 14 and 18 years in Jimma, Ethiopia, were included in the study. The data for the study were collected using a questionnaire. The questionnaire was intended to assess the knowledge, attitude, and practices toward oral hygiene among these young children.

Results: The results were statistically analyzed and the corresponding percentages were calculated. Regarding the knowledge toward oral hygiene, $55.2 \%$ of patients believed that oral health had a role in general health, only $16.4 \%$ thought irregular toothbrushing can cause tooth decay, only $26.9 \%$ opined that brushing properly prevents dental problems, and $26.7 \%$ did not know that dentists can clean and polish teeth. Attitude toward oral hygiene showed $92.2 \%$ of them had never visited a dentist and $21.4 \%$ did not think it is required to visit a dentist. Regarding the practice toward oral hygiene, only $14.13 \%$ used toothbrush and toothpaste and $72.41 \%$ cleaned using Mefakiya sticks and they change their brush only when the bristles get frayed up.

Conclusion: Students lacked awareness about oral health and its relation to general health. The importance of oral health and its maintenance needed to be emphasized. Currently, there is a lack of resources and educational programs on oral health. There is a need for dentists and public health workers to spread awareness among children in this region.

Keywords: Attitude, Knowledge, Oral hygiene, Schoolchildren, Toothbrushing.

Journal of Oral Health and Community Dentistry (2021): 10.5005/jp-journals-10062-0094
\end{abstract}

\section{INTRODUCTION}

The World Health Organization (WHO) fact sheet on oral health unveils that $60-90 \%$ of schoolchildren are affected by dental caries. Oral diseases, especially among children in poor and disadvantaged sections of the population, are higher. The general risk factors include poor oral hygiene and other social determinants that can have an adverse impact. ${ }^{1}$ This can lead to issues with mastication, communication, and smile due to loss, discoloration, or disfigurement of teeth, which in turn can have a larger impact on the general wellness of the individual. It can also lead to the loss of millions of school hours across the globe. ${ }^{2}$ Oral hygiene methods used in a suitable way in combination with professional care can be an effective means to avoid dental caries and periodontal diseases. ${ }^{3}$

Oral hygiene regulates the health of the oral cavity in an individual. ${ }^{4}$ The American Dental Association recommends that brushing of teeth two times a day combined with flossing at least once a day is an important aspect of preventing the risk of most oral infections. ${ }^{5}$ It is concerning that children, especially in developing nations, and particularly those in the disadvantaged sections are susceptible to poor oral health which is avoidable by following simple and inexpensive measures. ${ }^{6}$ The frequency of toothbrushing shows considerable variations across the globe. There has been a marked improvement in oral health in Europe, though certain parts, especially in Central and Eastern Europe, show little improvement, particularly in the deprived socioeconomic communities. The habit of brushing the teeth more than once a day varied from 75 to $45 \%$ between the
${ }^{1}$ Department of Dental Public Health, The University of Manchester, Manchester, England, United Kingdom

${ }^{2}$ School of Dentistry and Oral Health, Fiji National University, Fiji

${ }^{3}$ Department of Periodontology, Jimma University of Health Sciences, Jimma, Ethiopia

${ }^{4}$ Department of Dental Technology, King Khalid University, Abha, Kingdom of Saudi Arabia

${ }^{5}$ All Care Dental Center, Bengaluru, Karnataka, India

${ }^{6}$ Department of Pedodontics, Goa Dental College and Hospital, North Goa, Goa, India

Corresponding Author: Renu Rawat, Department of Dental Public Health, University of Manchester, Manchester, England, United Kingdom, e-mail: renurawataswal1@gmail.com

How to cite this article: Rawat R, Aswal GS, Kumar VKR, et al. A Crosssectional Assessment of Knowledge, Attitude, and Practices toward Oral Hygiene among Schoolchildren in Jimma, Ethiopia. J Oral Health Comm Dent 2021;15(1):1-6.

Source of support: Nil

Conflict of interest: None

countries in Europe. ${ }^{7}$ In Norway, brushing once a day was as high as $95 \%$ among 4- to 6 -year-old children. ${ }^{8}$ In the United States, $70 \%$ of the population brushes at least twice a day. ${ }^{9}$ However, an international study comprising parents of nearly 3,000 children observed that there were large variations between nations as well as between different

(0) The Author(s). 2021 Open Access This article is distributed under the terms of the Creative Commons Attribution 4.0 International License (https:// creativecommons.org/licenses/by-nc/4.0/), which permits unrestricted use, distribution, and non-commercial reproduction in any medium, provided you give appropriate credit to the original author(s) and the source, provide a link to the Creative Commons license, and indicate if changes were made. The Creative Commons Public Domain Dedication waiver (http://creativecommons.org/publicdomain/zero/1.0/) applies to the data made available in this article, unless otherwise stated. 
racial/ethnic groups. ${ }^{10}$ The study also concluded that attitudes and beliefs of parents also played an important role in the behavior of the children toward oral health. ${ }^{11}$ The health scenario of the African region shows a worrisome picture as the area is burdened by the paucity of financial and technical resources. ${ }^{12}$ Contrary to popular belief, the prevalence of dental caries is low but the profile of other oral diseases is varied across Africa and oral diseases in communities differ both in prevalence and severity. The DMFT (decayed, missing, or filled teeth) scores according to the national surveys are quite low (0.0-0.1 according to 2,000 figures from 39 sub-Saharan African countries) and it points to the fact that most of it were due to the lack of treatment due to inadequate oral healthcare systems. ${ }^{12}$

There is an overall paucity of information pertaining to community-based oral health status studies in Ethiopia. ${ }^{13}$ The WHO has come out with Promoting Oral Health in Africa, a manual, as a plan to prevent and manage oral diseases at the primary health care level across 47 countries. ${ }^{14}$ It includes a set of 10 protocols for the diagnosis and treatment of specific oral diseases. Moreover, for effective implementation, it is also important to know the current level of awareness and attitude toward oral health. Therefore, this study was designed to determine the knowledge, attitude, and behavior of schoolchildren in Jimma, Ethiopia, toward oral health.

\section{Materials and Methods}

This descriptive study comprised 580 schoolchildren in the agegroup of 14 to 18 years, studying in 9th to 12th grade. The study was aimed to assess the knowledge, attitude, and practices toward oral hygiene. The School of Dentistry, Jimma University, Jimma, Ethiopia, conducted a first-ever "School Oral Health Program-Brighter Smiles-Ethiopia" on January 25, 2020, at the Community School, Jimma University Main Campus, Jimma, Ethiopia. Educational lectures on oral health were conducted. The educational presentations were done by interns of the Jimma University in the local language with many animated illustrations and pictures. The interns were trained by specialists on oral health presentations before delivering them to the students. Before the presentations, to assess the students' knowledge, attitude, and practice toward oral health, three questionnaires with a total of 20 questions were distributed to the students. The questionnaires were translated into the local language "Amharic" by a professional translator for ease of understanding the questions. The consent to conduct the program was obtained from the Jimma University and the community school management.

\section{Questionnaires}

The questionnaires were divided into three topics, namely knowledge, attitude, and practice toward oral health, and had multiple-choice questions. The questions pertained to oral health and its role in general health, toothbrushing, the role of the dentist in the maintenance of general health, and knowledge about oral health and care. A total of 580 questionnaires were distributed among the children and the answers were collected.

\section{Results}

The responses from the samples were collected and percentages were calculated and inferences were drawn. The survey provided meaningful insight into knowledge, attitude, and practice toward oral health among children aged between 14 and 18 years in Jimma, Ethiopia. Table 1 pertained to the knowledge toward oral hygiene. Only $55.2 \%$ of the children responded that oral health had a role in
Table 1: Knowledge toward oral hygiene among schoolchildren in Jimma, Ethiopia

\begin{tabular}{|c|c|c|c|}
\hline Q. No. & Question & Total & $\%$ \\
\hline \multirow[t]{4}{*}{1.} & $\begin{array}{l}\text { Does oral health have any role in general } \\
\text { health? }\end{array}$ & & \\
\hline & a. Yes & 320 & 55.2 \\
\hline & b. No & 25 & 4.3 \\
\hline & c. Don't know & 235 & 40.5 \\
\hline \multirow[t]{7}{*}{2.} & What does irregular toothbrushing cause? & & \\
\hline & a. Decay & 95 & 16.4 \\
\hline & b. Gum disease & 120 & 20.7 \\
\hline & c. Bad breath & 125 & 21.6 \\
\hline & d. Stains on teeth & 105 & 18.1 \\
\hline & e. Nothing & 28 & 4.8 \\
\hline & f. All of the above & 107 & 18.4 \\
\hline \multirow[t]{6}{*}{3.} & Why do we get dental problems? & & \\
\hline & a. Eating sweets and ice creams & 90 & 15.55 \\
\hline & b. Not brushing properly & 112 & 19.3 \\
\hline & c. Not rinsing the mouth & 189 & 32.6 \\
\hline & d. Not regularly visiting a dentist & 20 & 3.45 \\
\hline & e. All of the above & 169 & 29.1 \\
\hline \multirow[t]{6}{*}{4.} & How can we prevent dental problems? & & \\
\hline & a. Avoiding sweets and sticky foods & 94 & 16.2 \\
\hline & b. Brushing properly & 156 & 26.9 \\
\hline & c. Mouth rinsing after meals & 204 & 35.2 \\
\hline & d. Regularly visiting a dentist & 38 & 6.5 \\
\hline & e. All of the above & 88 & 15.2 \\
\hline \multirow[t]{3}{*}{5.} & $\begin{array}{l}\text { Do you know that a clean mouth can prevent } \\
\text { tooth decay? }\end{array}$ & & \\
\hline & a. Yes & 385 & 66.4 \\
\hline & b. No & 195 & 33.6 \\
\hline \multirow[t]{3}{*}{6.} & $\begin{array}{l}\text { Do you know that a dentist can clean and } \\
\text { polish your teeth? }\end{array}$ & & \\
\hline & a. Yes & 425 & 73.3 \\
\hline & b. No & 155 & 26.7 \\
\hline \multirow[t]{6}{*}{7.} & $\begin{array}{l}\text { What can be prevented by regular cleaning of } \\
\text { the mouth? }\end{array}$ & & \\
\hline & a. Bleeding from gums & 43 & 7.4 \\
\hline & b. Loosening of gums & 50 & 8.6 \\
\hline & c. Loss of teeth & 40 & 6.9 \\
\hline & d. Bad smell & 65 & 11.2 \\
\hline & e. All of the above & 382 & 65.9 \\
\hline
\end{tabular}

general health but $40.5 \%$ of them did not know that it had any role. About $18.4 \%$ of the students concurred that irregular brushing can cause decay of teeth, gum disease, bad breath, and stains on teeth and $29 \%$ believed that dental problems arise due to eating sweets and ice creams, improper brushing, and not rinsing the oral cavity. Around $66.4 \%$ of them concluded that a clean mouth can prevent tooth decay and an astonishing $26.7 \%$ of them did not know that dentists could clean and polish teeth.

In Table 2, the survey was about the attitude toward oral hygiene and about $89.8 \%$ believed that maintaining oral health was an individual responsibility. Almost $92.2 \%$ of the children had never visited a dentist before and the main reason for the visit was 
Table 2: Attitude toward oral hygiene among schoolchildren in Jimma, Ethiopia

\begin{tabular}{|c|c|c|c|}
\hline Q. No. & Question & Total & $\%$ \\
\hline \multirow[t]{3}{*}{1.} & $\begin{array}{l}\text { Do you think maintaining a healthy mouth is } \\
\text { an individual responsibility? }\end{array}$ & & \\
\hline & a. Yes & 521 & 89.8 \\
\hline & b. No & 59 & 10.2 \\
\hline \multirow[t]{3}{*}{2.} & Have you visited a dentist before? & & \\
\hline & a. Yes & 45 & 7.8 \\
\hline & b. No & 535 & 92.2 \\
\hline \multirow[t]{6}{*}{3.} & If yes, then for what reason? & & \\
\hline & a. Decay & 4 & 8.88 \\
\hline & b. Pain & 31 & 68.88 \\
\hline & c. Filling & - & 0 \\
\hline & d. Extraction & 10 & 22.22 \\
\hline & e. Any others, specify & - & 0 \\
\hline \multirow[t]{3}{*}{4.} & $\begin{array}{l}\text { Do you think it is required to visit a dentist } \\
\text { periodically to maintain oral health? }\end{array}$ & & \\
\hline & a. Yes & 456 & 78.6 \\
\hline & b. No & 124 & 21.4 \\
\hline
\end{tabular}

due to pain and it measured $68.88 \%$ followed by extraction in about $22.22 \%$. However, about $78.6 \%$ of them did believe that a periodic visit to a dentist is necessary to maintain oral health.

In Table 3, the last part of the survey, practice toward oral hygiene among the children was assessed. A majority of close to $72.41 \%$ used Mefakiya sticks. Almost $90.34 \%$ of them cleaned their teeth once daily. The preferred style of brushing was using vertical strokes in about $64.3 \%$. Some children change their brush when the bristles get frayed up and this was observed in $60.7 \%$. About $96.34 \%$ of them applied the paste to the full-length of the bristles and $0 \%$ of them pressed the paste in between the bristles. When questioned, all $100 \%$ of them rinsed their mouth after meals and $88.4 \%$ of them did not clean their tongue and $67.2 \%$ of them used fingers to clean it.

\section{Discussion}

Dental caries along with periodontal disease are perceived as major contributors to the global burden of oral health. Although it is more prevalent in the industrialized world, it also has affected the population in Asian and Latin American countries. Although Africa is less affected, it is anticipated that there will be a spur as the level of sugar consumption increases and the use of fluorides decreases. ${ }^{15,16}$

Though environmental factors have a major impact on oral health and diseases, it is noted in the recent epidemiological surveys that sociobehavioral factors also contribute apart from factors like poverty, dietary habits, and poor nutrition. ${ }^{6}$ Children, especially in the developing world, are at a disadvantage due to inadequate resources and access to oral care. However, it is possible to prevent poor oral health by modes of knowledge that are easy to comprehend and by utilizing inexpensive basic healthcare practices.

The present study was conducted in Jimma, Ethiopia, because according to us no such study has been performed in the past in this specific age-group in the country. The study was designed in a way to know the knowledge, attitude, and practices that may help us provide better insights into local understanding of practices.
Table 3: Practice toward oral hygiene among schoolchildren in Jimma, Ethiopia

\begin{tabular}{|c|c|c|c|}
\hline Q. No. & Question & Total & $\%$ \\
\hline \multirow[t]{6}{*}{1.} & How do you clean your teeth? & & \\
\hline & a. Toothbrush and toothpaste & 82 & 14.13 \\
\hline & b. Toothbrush and tooth powder & 2 & 0.34 \\
\hline & c. Finger and tooth powder & 45 & 7.76 \\
\hline & d. Mefakiya sticks & 420 & 72.41 \\
\hline & e. Any others, specify & 31 & 5.34 \\
\hline \multirow[t]{5}{*}{2.} & How often do you clean your teeth? & & \\
\hline & a. Once daily & 524 & 90.34 \\
\hline & b. Twice daily & 18 & 3.1 \\
\hline & c. More than twice daily & 28 & 4.83 \\
\hline & d. After every meal & 10 & 1.72 \\
\hline \multirow[t]{5}{*}{3.} & How do you brush your teeth? & & \\
\hline & a. Use horizontal strokes & 11 & 13.1 \\
\hline & b. Use vertical strokes & 54 & 64.3 \\
\hline & c. Both in horizontal and vertical directions & 5 & 5.9 \\
\hline & d. Circular strokes & 14 & 16.7 \\
\hline \multirow[t]{6}{*}{4.} & How often do you change your brush? & & \\
\hline & a. Once in 3 months & - & 0 \\
\hline & b. Once in 6 months & 15 & 17.9 \\
\hline & c. Yearly once & 14 & 16.7 \\
\hline & d. When bristles get frayed up & 51 & 60.7 \\
\hline & e. Don't know exactly & 4 & 4.7 \\
\hline \multirow[t]{4}{*}{5.} & $\begin{array}{l}\text { What amount of paste do you apply to your } \\
\text { brush? }\end{array}$ & & \\
\hline & a. Full-length of bristles & 79 & 96.34 \\
\hline & b. Half-length of bristles & 2 & 2.44 \\
\hline & c. Pea-sized amount & 1 & 1.22 \\
\hline \multirow[t]{3}{*}{6.} & $\begin{array}{l}\text { Do you press the paste in between the } \\
\text { bristles? }\end{array}$ & & \\
\hline & a. Yes & - & 0 \\
\hline & b. No & 82 & 100 \\
\hline \multirow[t]{4}{*}{7.} & Do you rinse your mouth after meals? & & \\
\hline & a. Yes & 580 & 100 \\
\hline & b. No & - & 0 \\
\hline & c. Sometimes & - & 0 \\
\hline \multirow[t]{3}{*}{8.} & Do you clean your tongue? & & \\
\hline & a. Yes & 67 & 11.6 \\
\hline & b. No & 513 & 88.4 \\
\hline \multirow[t]{5}{*}{9.} & How do you clean your tongue? & & \\
\hline & a. Tongue cleaner & 7 & 10.4 \\
\hline & b. Fingers & 45 & 67.2 \\
\hline & c. Toothbrush & 13 & 19.4 \\
\hline & d. Any others, specify & 2 & 2.99 \\
\hline
\end{tabular}

According to Ismail Abbas Darout, who performed a study on knowledge and behavior among Jimma University Health Sciences students in 2014, he concluded that although awareness was higher among selected samples, there were misconceptions. ${ }^{17}$

In our study, the students were able to participate and complete the questionnaires accurately which itself indicates their keenness to know about oral health issues. A similar study 
by Satish Vishwanathaiah assessed the knowledge, attitude, and behavior of schoolchildren in Davangere, India, and he too found that children were aware of oral health importance.

Good health practices essentially depend on self-care habits, utilization of dental services, oral health education, and professional preventive measures. ${ }^{18}$ In this study, knowledge toward oral hygiene was assessed as it decides good oral health practices and we noted that the majority of them (55.2\%) thought that oral health has a role in general health although a significant number $(40.5 \%)$ did not know about it.

With respect to the consequences of irregular toothbrushing, $21.6 \%$ of them opined that it caused bad breath which was $5 \%$ higher than the awareness about tooth decay (16.4\%). The survey showed that $32.6 \%$ of them thought that not rinsing the mouth was the main reason to obtain dental problems but only $3.45 \%$ of them believed that not visiting a dentist regularly can be a problem. Even for the question about preventing dental problems, mouth rinsing after a meal (35.2\%) was considered top priority and along with it avoiding sweets and sticky foods and brushing properly were considered important; however, a regular visit to a dentist was the last priority (6.5\%) (Fig. 1). This indicates that further enhancement of knowledge with respect to benefits as well as consequences of proper brushing and obtaining professional healthcare services is indicated. It is possible that fear of and anxiety while going to a dentist can affect a majority of children and adolescents and this can be a considerable barrier. ${ }^{19} \mathrm{~A}$ study in Japan by Takaaki et al. opined that dental clinic was the common source of dental knowledge that resulted in better oral health behavior among university students. ${ }^{20}$

Also, $66.4 \%$ of them knew that a clean mouth can prevent tooth decay, only $26.9 \%$ believed that brushing properly can prevent a dental problem which indicates inadequate knowledge about preventive measures. In our study, about $73 \%$ of them did not even know that a dentist could clean and polish teeth. However, $65.9 \%$ of them thought that bleeding from the gums, loosening of gums, loss of teeth, and bad smell can all be prevented by regular cleaning of the mouth. By imparting better knowledge about oral hygiene and improved health practices, it is possible to improve oral hygiene in children. ${ }^{6}$ Also, the central component of the WHO HealthPromoting School Model rests on the provision of knowledge and teaching/reinforcing healthy practices. Oral health education can be an effective method to improve knowledge, attitude, and practice to improve health as noted in a review by Nakre et al. ${ }^{21}$

The assessment of the attitude of schoolchildren revealed that a majority of $89.8 \%$ believed that maintaining a healthy mouth is an individual responsibility. It was noted that $92.2 \%$ of them had never visited a dentist before and if they had visited around $68.88 \%$ of them were for dental pain and none of them had visited for a filling. A combined value of $30 \%$ of them had visited for decay or extraction with the latter sharing the higher percentage. It was observed that $78.6 \%$ wanted to visit a dentist periodically to maintain oral health (Fig. 2). The lack of awareness regarding the role of a dentist and the importance of preventive measures combined with a deficiency of proper oral education can be observed. Also, it is recognized that parental behavior affects their children's oral health. It is possible to make a difference in their children's oral health by imparting the right knowledge and attitude to parents. ${ }^{22}$ In a study conducted in Greece, it was noted that barriers to applying oral hygiene methods included boredom, ignorance about its importance, and forgetfulness. ${ }^{23}$ Therefore, the focus should be on ways to motivate the children about proper oral hygiene.

The practice toward oral hygiene showed that $72.41 \%$ depended on Mefakiya sticks for cleaning and only $14.13 \%$ used toothbrush and toothpaste. This finding was in unison with another study in Ethiopia by Ismail Abbas Darout who noted that Mefakiya stick usage was equal to toothbrushing practice among university students. ${ }^{17}$ A study by Malik et al. observed that chewing sticks at times provides improved mechanical and chemical cleaning as compared to a toothbrush. ${ }^{24}$ Brushing teeth at least one time per day was observed between $90.34 \%$ and only $3.1 \%$ brushed twice daily (Fig. 3). This further advances our belief that parental guidance is an important aspect of improved oral hygiene behavior. While brushing, $64.3 \%$ of them used vertical strokes and $60.7 \%$ of them changed brush only when the bristles frayed up. Patil et al. have opined that a modified bass technique was the best method of brushing in children and there is a need to impart the right knowledge for students. ${ }^{25}$ Also, the regular interval for changing a toothbrush is once in 3 months and the students were unaware of it. ${ }^{26}$ Regarding the amount of paste applied, $96.34 \%$ of them applied it along the full-length of the brush but none of them pressed the paste between the bristles. It was impressive to note that $100 \%$ of

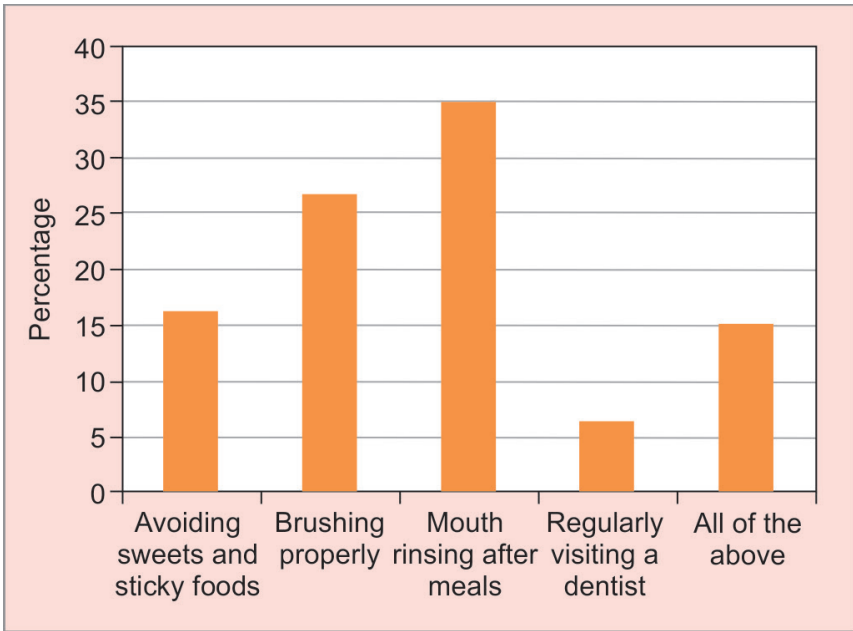

Fig. 1: Respondents'knowledge toward prevention of dental problems

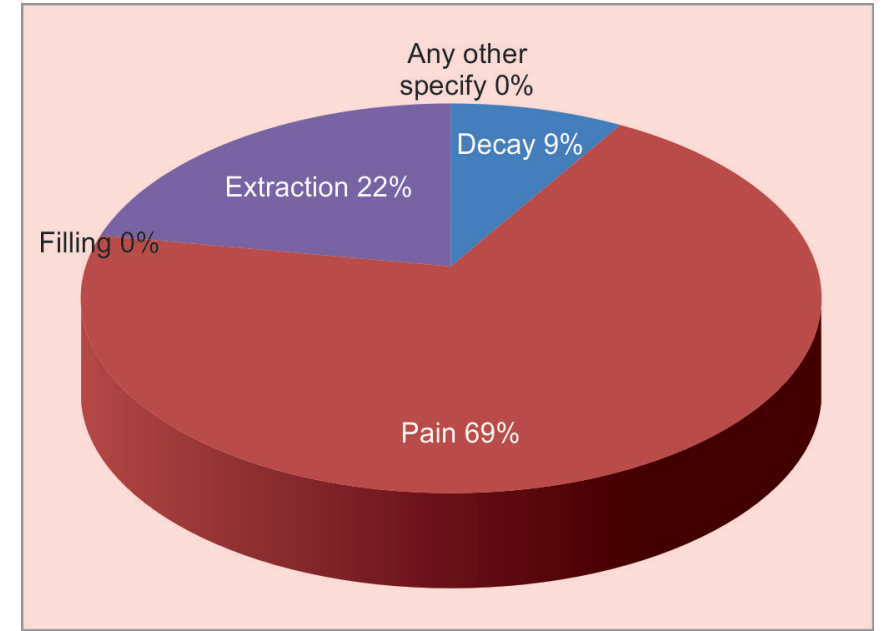

Fig. 2: Respondents' attitude toward visiting a dentist 


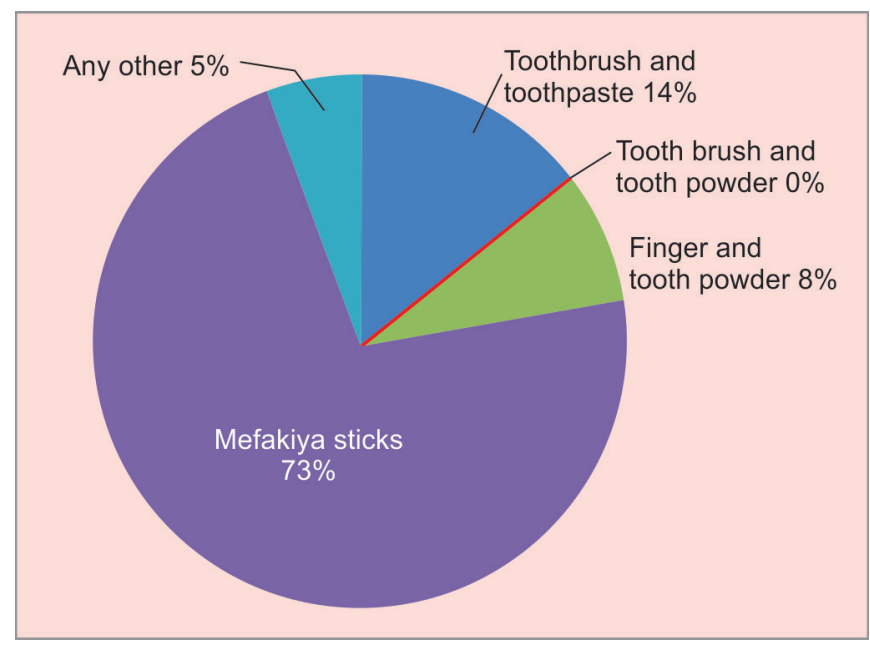

Fig. 3: Respondents' practice toward oral hygiene modalities

them rinsed their mouth after meals but $88.4 \%$ of them did not clean their tongue and only $10.4 \%$ used a tongue cleaner. The above clearly indicates a need for a holistic, regular school oral health education program to provide information about right habits.

Oral health care in Africa is affected by an imbalance in the needs of the population and oral care personnel, higher cost of treatment, unreliable services, and general low priority to oral health care due to the pressing general health problems. ${ }^{12}$ Various past approaches were based on models developed by developed nations. The problems are unique and therefore the solutions need to be specific. There is a general lack of policies and plans on oral health, poorly trained dentists, curative-based approach, and the lack of adequate materials and equipment. ${ }^{12,27}$

The WHO Regional Office for Africa in its 48th session as early as 1998 had adopted that the future strategies should focus on districts and communities where special emphasis was given on children, pregnant women, and vulnerable groups where prevention of oral disease received higher priority. Al-Omari and Vishwanathaiah in separate studies have stressed decreasing the dependency on oral health professionals and improve the children to show improved responsibilities for their own health. We too concur with their observation. ${ }^{26,28}$ Oral health is an important aspect of health and maintenance is extremely important. Even in Jimma, similar to other studies in Africa, the studies concur with the fact that there is a lack of resources, the dearth of oral health providers, and inadequate educational programs on health. Also, we observe that the focus is intended more toward curative like filling or extraction, and the emphasis is not shown on preventive measures. These measures are relatively easier if proper educational material and reinforcement are provided. It is also pertinent that the involvement of parents to motivate their children to practice the behavior consistently is important. Healthcare providers in conjunction with school health programs have an obligation to improve the awareness about the importance of oral health. This also warrants further researches and studies to better understand the disparities that may further arise due to ethnicity, gender, or tribe in the region.

\section{CONCLUSION}

The students lacked awareness about oral health and its relation to general health. The importance of oral health and its maintenance needed to be emphasized. Currently, there is a lack of resources and educational programs on oral health. There is a need for dentists and public health workers to spread awareness among children in the region. There is a need to support this initiation of School Oral Health Program-Brighter Smiles-Ethiopia to further reach out to a wider school population. This eventually will have a trickle-down effect that will raise awareness about the importance, maintenance, and preventive modalities for the improvement of oral health.

\section{Clinical Significance}

This article highlights the lack of awareness regarding oral health and the squeezing need to reduce the overall burden of dental diseases through educational interventions in Ethiopia.

\section{OrCID}

Gunjan S Aswal @ https://orcid.org/0000-0003-2641-1601

Dinesh F Swamy @ https://orcid.org/0000-0001-6426-0168

\section{References}

1. WHO. Oral health. April 2012.

2. Petersen $\mathrm{PE}$, Bourgeois $\mathrm{D}$, Ogawa $\mathrm{H}$, et al. The global burden of oral diseases and risks to oral health. Bull World Health Organ 2005;83(9):661-669. PMID: 16211157. PMCID: PMC2626328.

3. Choo A, Delac DM, Messer LB. Oral hygiene measures and promotion: review and considerations. Austr Dent J 2001;46(3):166-173. DOI: 10.1111/j.1834-7819.2001.tb00277.x.

4. Ravishankar PL, Jayapalan CS, Gondhalekar RV, et al. Prevalence of dental caries and oral hygiene status among school going children: an epidemiological study. J Contemp Dent Pract 2013;14(4):743-746. DOI: 10.5005/jp-journals-10024-1394.

5. ADA. American Dental Association statement on regular brushing and flossing to help prevent oral infections. American Dental Association; 2013 [03/17/2018]. Available from: https://www.ada.org/en/press-room/ news-releases/2013-archive/august/american-dental-associationstatement-on-regular-brushing-and-flossing-to-help-prevent-oral.

6. Macnab AJ. Children's oral health: the opportunity for improvement using the who health promoting school model. Adv Public Health 2015;2015:651836. DOI: 10.1155/2015/651836.

7. Eaton KA, Carlile MJ. Tooth brushing behaviour in Europe: opportunities for dental public health. Int Dent J 2008;58:287-293. DOI: 10.1111/j.1875-595X.2008.tb00206.x.

8. Wigen $\mathrm{TI}$, Wang NJ. Tooth brushing frequency and use of fluoride lozenges in children from 1.5 to 5 years of age. A longitudinal study. Commun Dent Oral Epidemiol 2014;42(5):395-403. DOI: 10.1111/ cdoe.12094.

9. ADA. Survey finds shortcomings in oral health habits. American Dental Association; 2014 [03/17/2018]. Available from: https://www. ada.org/en/publications/ada-news/2014-archive/october/surveyfinds-shortcomings-in-oral-health-habits.

10. Huebner CE, Riedy CA. Behavioral determinants of brushing young children's teeth: implications for anticipatory guidance. Pediatr Dent 2010;32(1):48-55. PMID: 20298653. PMCID: PMC2939855.

11. Pine $C M$, Adair PM, Nicoll AD, et al. International comparisons of health inequalities in childhood dental caries. Commun Dent Health 2004;21(1 Suppl.):121-130. PMID: 15072481.

12. Thorpe $\mathrm{S}$. Oral health issues in the African region: current situation and future perspectives. J Dent Educ 2006;70(11 suppl):8-15. DOI: 10.1002/j.0022-0337.2006.70.11_suppl.tb04209.x.

13. Simon C, Tesfaye F, Berhane Y. Assessment of the oral health status of school children in Addis Ababa. Ethiop Med J 2003;41(3):245-256. PMID: 15227890

14. Africa WROf. Promoting oral health in Africa: prevention and control of oral diseases and noma as part of essential noncommunicable disease interventions; 2016. 
15. Petersen PE. The burden of oral disease: challenges to improving oral health in the 21st century; 2005.

16. Petersen PE. The World Oral Health Report 2003: continuous improvement of oral health in the 21st century--the approach of the WHO Global Oral Health Programme. Commun Dent Oral Epidemiol 2003;31(Suppl. 1):3-23. DOI: 10.1046/j..2003.com122.x.

17. Darout I. Knowledge and behavior related to oral health among Jimma University Health Sciences students, Jimma, Ethiopia. Eur J Gen Dent 2014;3(3):185-189. DOI: 10.4103/2278-9626.141663.

18. Al-Darwish MS. Oral health knowledge, behaviour and practices among school children in Qatar. Dent Res J 2016;13(4):342-353. DOI: 10.4103/1735-3327.187885.

19. Chhabra N, Chhabra A, Walia G. Prevalence of dental anxiety and fear among five to ten year old children: a behaviour based cross sectional study. Minerva Stomatol 2012;61(3):83-89. PMID: 22402299.

20. Taniguchi-Tabata A ED, Mizutani S, et al. Associations between dental knowledge, source of dental knowledge and oral health behavior in Japanese university students: a cross-sectional study. PLoS One 2017;12(6):e0179298. DOI: 10.1371/journal.pone.0179298.

21. Nakre PD, Harikiran AG. Effectiveness of oral health education programs: a systematic review. J Int Soc Prev Commun Dent 2013;3(2):103-115. DOI: 10.4103/2231-0762.127810.
22. Bozorgmehr E, Hajizamani A, Mohammadi TM. Oral health behavior of parents as a predictor of oral health status of their children. ISRN Dent 2013;2013:741783. DOI: 10.1155/2013/741783.

23. Angelopoulou M, Kavvadia K, Oulis C, et al. Oral hygiene facilitators and barriers in Greek 10 years old schoolchildren. Int J Clin Pediatr Dent 2015;8(2):87-93. DOI: 10.5005/jp-journals-10005-1290.

24. Malik AS, Shaukat MS, Qureshi AA, et al. Comparative effectiveness of chewing stick and toothbrush: a randomized clinical trial. N Am J Med Sci 2014;6(7):333-337. DOI: 10.4103/1947-2714.136916.

25. Patil SP, Patil PB, Kashetty MV. Effectiveness of different tooth brushing techniques on the removal of dental plaque in 6-8 year old children of Gulbarga. J Int Soc Prev Community Dent 2014;4(2):113-116. DOI: 10.4103/2231-0762.138305.

26. Vishwanathaiah S. Knowledge, attitudes, and oral health practices of school children in Davangere. Int J Clin Pediatr Dent 2016;9(2):172-176. DOI: 10.5005/jp-journals-10005-1358.

27. World Health Organization, Regional Office for Africa. Oral health in the African region: a region strategy (1999-2008). Brazzaville, Republic of Congo: World Health Organization, Regional Office for Africa; 1998.

28. Al-Omiri MK, Al-Wahadni AM, Saeed KN. Oral health attitudes, knowledge, and behavior among school children in North Jordan. J Dent Educ 2006;70(2):179-187. PMID: 16478932. 